\title{
PERAN MEDIA AJAR DALAM PENDIDIKAN KEUANGAN PADA SISWA TAMAN KANAK-KANAK MELALUI PROGRAM SERVICE LEARNING MATA KULIAH PERSONAL FINANCE
}

\author{
Nanik Linawati \\ Program Manajemen Keuangan, Program Studi Manajemen, Fakultas Ekonomi \\ Universitas Kristen Petra \\ Л. Siwalankerto 121-131, Surabaya 60236 \\ Email: nanikl@petra.ac.id
}

\begin{abstract}
Abstrak: Pendidikan anak pada jenjang pendidikan Taman Kanak-kanak merupakan fondasi bagi pembentukan kepribadian pada jenjang usia berikutnya hingga dewasa. Salah satu materi pendidikan yang harus diberikan, yaitu pendidikan dalam mengelola uang, khususnya menanamkan kebiasaan menabung dan perasaan bangga pada kemampuan anak, karena memiliki kemampuan untuk membeli sesuatu yang diinginkan dari uang sendiri. Materi pendidikan yang juga penting untuk diberikan kepada siswa Taman Kanak-kanak, yaitu pengenalan terhadap uang sebagai instrumen transaksi sehari-hari. Media aktivitas yang dipilih untuk menanamkan kegemaran menabung melalui gerak dan lagu, cerita, panggung boneka, dan mewarnai. Sedangkan pengenalan terhadap uang disampaikan melalui media tutorial dengan menggunakan peraga dan role playing (bermain peran).
\end{abstract}

Kata kunci: media ajar, pendidikan keuangan, Taman Kanak-kanak.

Abstract: Kids' education in the kindergarten level is the foundation for the formation of personality in the upcoming level to adult. One of the educational materials to be supplied is education in managing money, especially in inculcating the habit of saving and a sense of pride in the ability of to buy something that is paid by their own money. Educational materials are also important to be given to the kindergarten pupils by means of the introduction of money as an instrument of daily transactions. Media activities were chosen to embed avocation saving through movement and song, stories, puppet shows, and coloring. While the introduction of the money was delivered through the tutorial using visual media and role playing.

Keywords: instructional media, financial education, kindergarten

\section{PENDAHULUAN}

Pendidikan anak pada jenjang Taman Kanakkanak memiliki peran penting dalam perkembangan kemampuan anak dalam jangka panjang. Materi-materi yang diajarkan kepada siswa Taman Kanak-kanak akan tertanam hingga usia dewasa (Wijayanti, 2008). Hasil penelitian menunjukkan bahwa sekitar lima puluh persen variabilitas kecerdasan orang dewasa sudah terbentuk pada saat anak berusia empat tahun. Selanjutnya peningkatan pertumbuhan sekitar tiga puluh persen terjadi pada usia delapan tahun, dan dua puluh persen sisanya pada pertengahan atau akhir dasawarsa kedua. Anak-anak mampu menyerap semua hal yang diajarkan pada saat berusia empat tahun, karena pada masa itu merupakan periode emas otaknya (Gunansyah, 2010).

Kementerian Pendidikan Nasional, Direktorat Jenderal Pendidikan Anak Usia Dini, Nonformal dan Informal menekankan nilai-nilai karakter yang perlu ditanamkan pada siswa didik meliputi: kecintaan terhadap Tuhan Yang Maha Esa. Kejujuran, disiplin, toleransi dan cinta damai, percaya diri, mandiri, tolong menolong, kerjasama, dan gotongroyong, hormat dan sopan santun, tanggung jawab, kerja keras, kepemimpinan dan keadilan, kreatif, rendah hati, peduli lingkungan, cinta bangsa dan tanah air (Kementerian Pendidikan Nasional, 2012). Sangat disayangkan materi pendidikan untuk menanamkan pengelolaan uang untuk anak sejak usia dini belum termasuk dalam kurikulum Taman Kanak-kanak. Oleh sebab itu Perguruan Tinggi yang menyelenggarakan program manajemen keuangan harus ikut berperan dalam mengisi kekosongan kurikulum dari aspek materi pembelajaran terkait pengelolaan keuangan.

Universitas Kristen Petra, khususnya Program Manajemen Keuangan Program Studi Manajemen Fakultas Ekonomi terdorong untuk mengambil 
bagian dalam menjawab tantangan tersebut dengan melakukan edukasi keuangan bagi siswa Taman Kanak-kanak melalui program Service Learning dengan menggunakan media ajar yang relevan untuk siswa Taman Kanak-kanak. Media ajar yang digunakan meliputi gerak dan lagu, cerita, panggung boneka, mewarnai, tutorial dengan menggunakan peraga dan role playing (bermain peran). Pemilihan media ajar tersebut didasarkan pada kemampuan menciptakan suasana kegembiraan dan besaran proporsi unsur bermain.

\section{KAJIAN PUSTAKA}

\section{Mengajar Anak tentang Uang}

Uang digunakan untuk membiayai kebutuhan setiap orang pada setiap jenjang usia. Oleh sebab itu selayaknya pengenalan terkait nilai uang dan cara pengelolaan uang secara bijak mulai diajarkan sejak usia dini.

\section{Memahami Nilai Uang}

Kebersamaan antara anak dan orang tua saat melakukan transaksi dapat menjadi lahan pembelajaran bagi anak tentang peran uang dalam kehidupan sehari-hari. Bentuk-bentuk memperkenalkan uang dapat melalui mengenalkan dengan bentuk fisik dan nilai nominal uang, mengajarkan untuk membayar sendiri, mengajarkan praktik menabung, dan mengajarkan membuat catatan anggaran belanja sederhana (Asuh Anak, 2014).

\section{Menggunakan uang dengan bijak}

Hidup di era moderen, setiap pribadi menghadapi tantangan yang tidak mudah, termasuk bagi guru dan orang tua dalam mendidik anak, khususnya terkait mengelola uang dengan bijak. Selain itu, guru dan orang tua harus mampu menanamkan pada benak anak perbedaan antara need dan want. Sehingga anak dapat disadarkan bahwa produk yang diiklankan di media internet, media elektronik ataupun media cetak bukanlah kebutuhan, namun ditujukan untuk mendorong keinginan anak untuk membeli produk tersebut (Mulyadi \& Trizki, 2012).

\section{Mengajar Pentingnya Menabung Bagi Anak}

Membiasakan anak menabung sejak dini akan mampu membentuk pribadi yang hemat, bertanggung jawab dan lebih menghargai uang. Menabung juga bermanfaat, untuk mengajar anak menahan diri, belajar membuat target dan perencanaan, serta meningkatkan interaksi dengan orangtua. Oleh sebab itu, menabung perlu diajarkan sejak dini agar karakter hemat dapat terbentuk dan terhindar dari perilaku konsumtif (Sitepu, 2013).

\section{Varian Media Ajar dalam Memotivasi Minat Menabung}

\section{Bermain Peran (Role Playing)}

Media ajar Role Playing memiliki peran penting dalam mengembangkan imajinasi anak. Usia anak merupakan usia yang diwarnai dengan imajinasi. Sehingga jika pada usia siswa TK diajarkan suatu perilaku yang positip melalui role playing, maka pemahaman terhadap konsep tersebut akan melekat hingga usia dewasa. Role Playing memupuk kemampuan siswa untuk: (1). belajar menirukan peristiwa di dunia nyata, (2). belajar tentang peran sosial, (3). belajar berinteraksi dengan orang lain, (4). belajar mengekspresikan kemampuan berbahasa, (5). belajar mengasah imajinasi, dan (6). meningkatkan rasa percaya diri (Nakita, 2016). Selain itu, penyampaian materi pembelajaran melalui media ajar bermain peran (role playing) merupakan hal yang sangat menyenangkan bagi siswa TK dan memberi dampak hasil yang optimal (Risnawati, 2012).

\section{Panggung Boneka}

Media ajar panggung boneka, pada saat disajikan melibatkan indera penglihatan dan pendengaran anak lebih efektif, karena dalam mengikuti sajian panggung boneka setiap anak harus mengintegrasikan kemampuannya dalam melihat dan mendengar, seperti penyampaian dalam bentuk ceramah (Rachmayanti, 2011). Sehingga penggunaan media ajar panggung boneka mampu meningkatkan daya serap anak dalam menagkap pesan yang disampaikan.

\section{Mendongeng}

Media ajar mendongeng sangat bermanfaat bagi anak untuk merekatkan hubungan pembawa cerita dengan anak, membantu mengoptimalkan perkembangan psikologis dan kecerdasan anak secara emosional, mengembangkan daya imajinansi anak, meningkatkan ketrampilan berbahasa (Bidanku, 2016) dan mampu meningkatkan perkembangan kecerdasan moral anak usia prasekolah (Ahyani, 2010).

\section{Mendongeng Merekatkan Hubungan}

Penggunaan media ajar mendongeng mampu meningkatkan interaksi emosional antara pembawa cerita dan anak sebagai pendengar cerita. Selama dongeng disampaikan anak dapat bertanya langsung terkait hal-hal yang tidak dipahami. Sebaliknya pembawa cerita secara terus menerus akan berusaha menyesuaikan cara menyampaikan dongeng dengan gaya yang disukai anak. Sehingga 
melalui dongeng pembawa cerita akan semakin akrab dan semakin mengenal karakter anak; sebaliknya, anak akan semakin mengenal karakter pembawa cerita.

\section{Mendongeng Mengoptimalkan Perkembangan Psikologis Anak}

Media ajar mendongeng membantu anak untuk mengembangkan imajinasi. Melalui dongeng, anak dibantu masuk ke dunia imajinasi dengan pesan seperti yang diinginkan sang pembawa cerita. Dengan daya imajinasi yang bagus ini, maka pembawa cerita harus dapat memanfaatkan dan mengarahkan anakanak ke arah yang positif (Verawati, 2015).

\section{Menggambar dan Mewarnai}

Media ajar mewarnai berperan untuk memberikan stimulasi motorik halus pada anak (Fadhilah, 2014). Menggambar dan mewarnai bermanfaat bagi pertumbuhan anak balita secara sosial. Bila aktivitas ini dilakukan secara berkelompok, anak akan saling berinteraksi dan berbincang-bincang dengan perbendaharaan kata yang dimiliki, yang secara tidak langsung akan melatih kemampuan verbal anak (Unilever, 2016).

\section{Gerak dan Lagu}

Media ajar Gerak dan Lagu merupakan media yang sesuai bagi anak pada usia 5-6 tahun yang memiliki potensi besar untuk dikembangkan. Salah satu potensi yang dimiliki anak pada usia ini, yaitu potensi motorik fisik dalam bentuk melompat, berjalan, bertepuk tangan, melambaikan tangan. Melalui gerak dan lagu dapat ditanamkan nilai yang positip dengan cara yang menyenangkan, namun berdampak menetap pada memori anak dalam jangka panjang (Fitriani \& Reza, 2013).

\section{METODOLOGI}

Teknik yang diterapkan meliputi observasi, wawancara, dan kaji tindak yang dilakukan oleh mahasiswa dan dosen yang terlibat dalam program service learning pada mata kuliah Personal Finance di kelurahan Siwalankerto dan Pondok Chandra. Teknik observasi dan wawancara digunakan untuk memperoleh data dan gambaran terkait karakteristik dan kebutuhan siswa Taman Kanak-kanak. Berdasarkan data dan informasi yang diperoleh, kemudian dipilih media ajar yang tepat untuk memberikan edukasi tentang nilai uang dan pentingnya menabung yang sesuai dengan kebutuhan siswa Taman Kanak-kanak.

\section{HASIL DAN PEMBAHASAN}

Tabel 1. Taman Kanak-Kanak Lokasi Service Learning

\begin{tabular}{cccc}
\hline $\begin{array}{c}\text { No. } \\
\text { Kelom- } \\
\text { pok }\end{array}$ & $\begin{array}{c}\text { Taman Kanak-kanak } \\
\text { yang Dilayani }\end{array}$ & $\begin{array}{c}\text { Jumlah } \\
\text { Siswa TK } \\
\text { (orang) }\end{array}$ & $\begin{array}{c}\text { Jumlah } \\
\text { (ana TK }\end{array}$ \\
\hline 1 & TK. Kyai Ibrahim 1-A & 66 & 9 \\
2 & TK. Islam Nur Azizi 3 & 25 & 4 \\
3 & TK. Az-Zahro & 30 & 3 \\
4 & TK. Karya Widya & 25 & 3 \\
5 & TK. Hidayatullah & 68 & 4 \\
\hline
\end{tabular}

Sumber: Laporan Service Learning Mahasiswa

\section{Bermain Peran (Role Playing)}

Media ajar yang dipilih untuk mengajarkan anak tentang nilai uang disampaikan juga melalui bermain peran. Siswa Taman Kanak-kanak diberikan uang tiruan yang mirip dengan uang Republik Indonesia yang resmi sebanyak dua puluh ribu dalam pecahan sepuluh ribu, lima ribu, dua ribu, dan seribu. Mahasiswa mempersiapkan bermacam-macam snack, kue dan permen dan berperan sebagai penjual. Para siswa TK dapat membelanjakan uangnya untuk membeli makanan yang diinginkan dengan membayar sebesar harga yang tercantum pada label harga. Jika siswa membayar lebih besar dari harga makanan, maka akan menerima uang kembali. Melalui permainan peran, siswa TK belajar mengenali ciri-ciri setiap uang pecahan yang dimiliki dan belajar tentang nilai uang. Media ajar bermain peran merupakan media yang efektif dalam meningkatkan pemahaman siswa TK terhadap nilai uang.

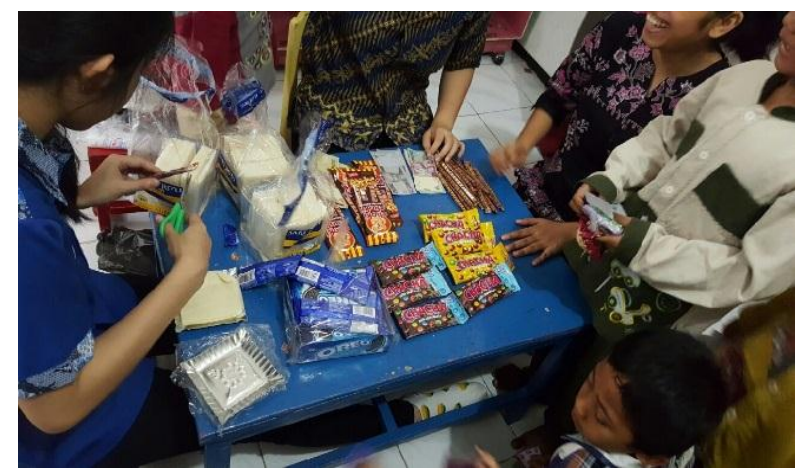

Gambar 1. Role Play Transaksi

\section{Panggung Boneka}

Panggung boneka merupakan pertunjukan yang sangat dinantikan oleh siswa TK. Sebelum pertunjukan panggung boneka ditampilkan para siswa TK sudah duduk dengan rapi. Melalui aktivitas panggung boneka mahasiswa dapat berinteraksi langsung dengan siswa TK melalui tokoh yang diperankan oleh setiap boneka. Tema yang dipilih "Menabung Uang Menabung Mimpi”. Setiap boneka memerankan tokoh yang memiliki sifat 
tertentu. Ada tokoh yang memerankan anak yang boros, ada pula tokoh yang memerankan anak yang hemat. Melalui dialog yang dikembangkan, akhirnya anak yang hemat dapat meyakinkan anak yang boros untuk mulai menabung. Penggunaan media ajar boneka memiliki kelebihan dalam hal merepresentasikan diri siswa pada tujuan yang diinginkan, yaitu rajin menabung.

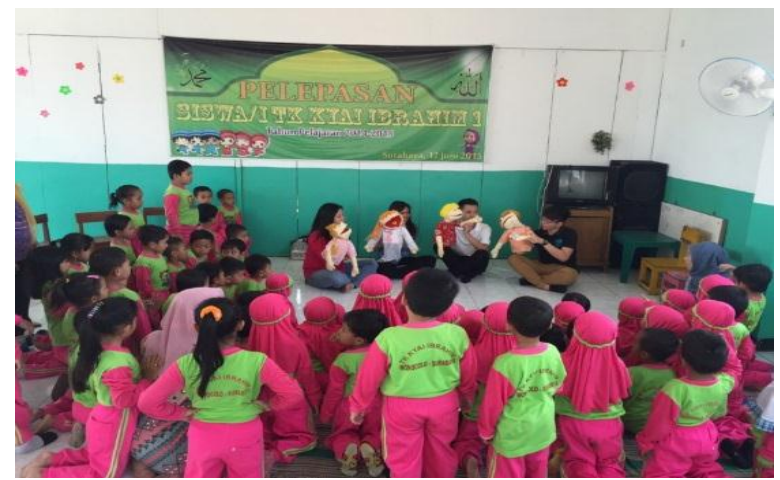

Gambar 2. Panggung Boneka "Ayo Menabung”

\section{Mewarnai Gambar}

Mewarnai gambar barang-barang yang dapat dibeli dari uang hasil menabung mampu membangkitkan minat menabung di dalam diri anak (biMBA AIUEO, 2013). Selama aktivitas mewarnai berlangsung, anak akan terus berinteraksi dengan gambar barang yang diinginkan, sehingga imajinasi anak tentang menabung akan semakin diperkuat. Penguatan imajinasi dalam diri anak akan menumbuhkan motivasi untuk menabung.

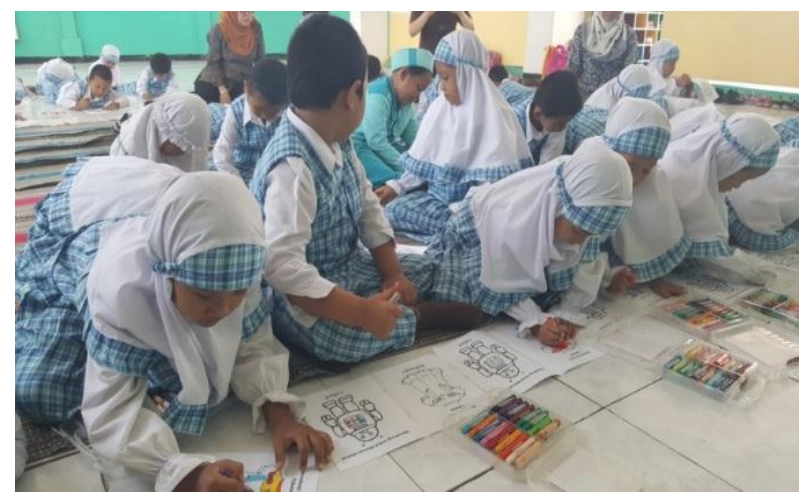

Gambar 3. Mewarnai Barang Kesukaan Anak

\section{Mendongeng}

Dongeng yang dibawakan memiliki tujuan agar siswa TK termotivasi untuk terus menabung hingga barang-barang yang diinginkan dapat terbeli dengan uang yang ditabung. Kisah yang disajikan mengisahkan success story tentang seorang anak yang bisa mendapatkan barang yang diidamidamkan sejak lama dari hasil ketekunannya menabung dari sehari ke sehari hingga terkumpul uang dalam jumlah yang cukup. Mahasiswa sebagai pembawa cerita, mengekspresikan kekagumannya pada tokoh dalam cerita, karena berhasil untuk mengendalikan keinginan untuk menggunakan uang sakunya untuk jajan.

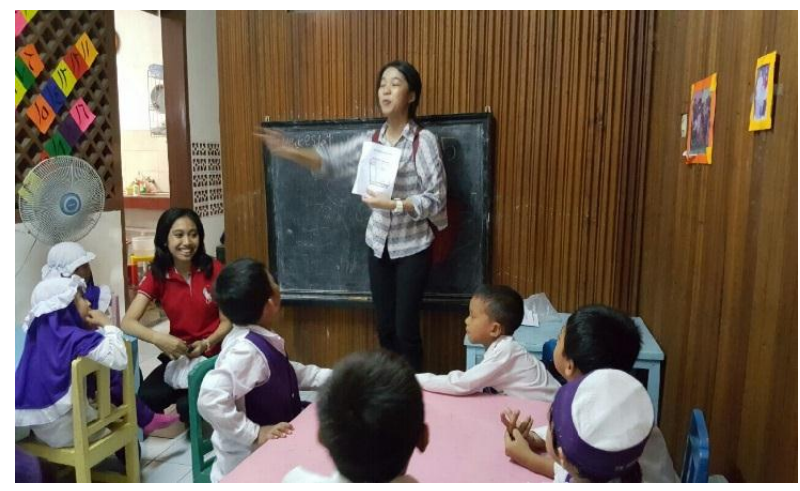

Gambar 4. Mendongeng “Menabung itu Asyik”

\section{Edukasi tentang Nilai Uang}

Siswa TK perlu mengetahui besaran uang yang umum digunakan untuk transaksi sehari-hari, agar dapat menggunakannya secara tepat. Sebagai jawaban atas kebutuhan tersebut, program Service Learning memberikan pengetahuan kepada para siswa TK tentang perbedaan uang logam dan uang kertas, cara mengenali nilai uang berdasarkan warna dan nominalnya. Untuk mendukung keberhasilan penyampaian materi yang diberikan, mahasiswa membuat game interaktif dengan menggunakan kartu bermain yang bertujuan, agar siswa TK lebih memahami konsep uang. Berdasarkan hasil evaluasi, game pengenalan nilai uang dinilai efektif sebagai media ajar, karena para siswa TK mampu membedakan ciri-ciri fisik setiap nominal uang dan nilai tukarnya.

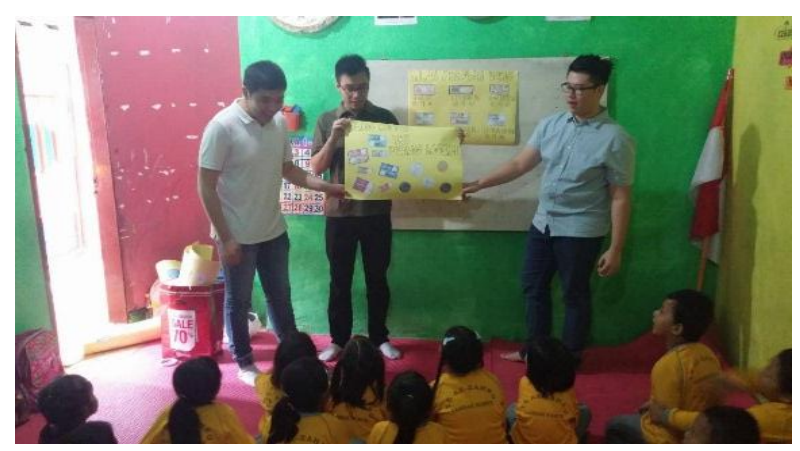

Gambar 5. Memperkenalkan Nilai Uang

\section{Mempraktekkan Kegiatan Menabung}

Kegiatan edukasi akan lebih mudah dipahami jika disertai praktek. Pada kegiatan service learning, para mahasiswa melakukan tindak lanjut edukasi menabung dengan membagikan celengan. Sebelum menerima celengan, para siswa TK diminta bercerita singkat tentang apa yang ingin 
dibelinya dengan uang hasil tabungan, dan para siswa bersedia bercerita di depan kelas satu per satu terkait harapan benda yang ingin dibeli dengan uang hasil tabungan. Sebagai apresiasi diberikan snack kepada setiap siswa yang bersedia bercerita. Setelah itu celengan dibagikan kepada setiap siswa. Siswa yang masih memiliki sisa uang saku, diminta untuk langsung memasukkan uangnya ke dalam celengan. Media praktek menabung efektif untuk memperkuat motivasi siswa TK dalam menabung.

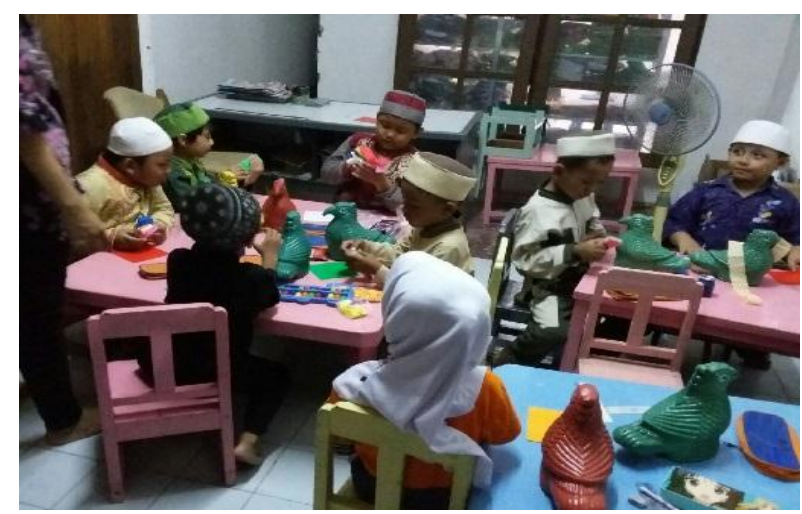

Gambar 6. Menghias Celengan

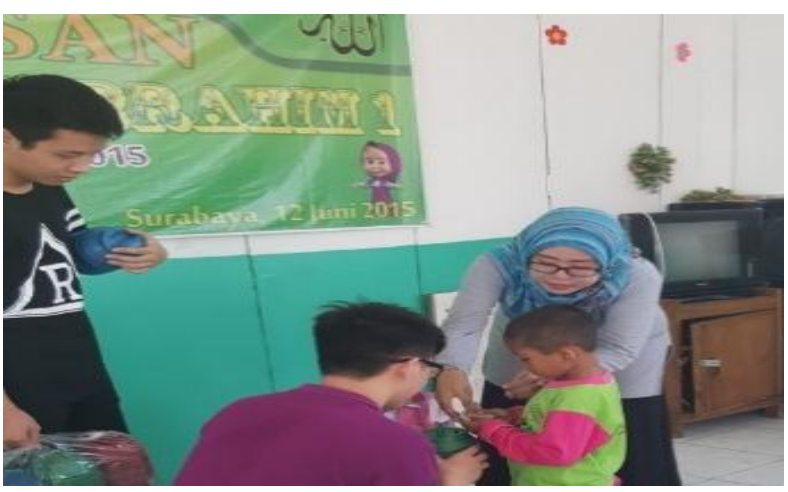

Gambar 7. Mempraktekkan Menabung

\section{REKOMENDASI}

Pemanfaatan media ajar untuk memotivasi para siswa TK untuk rajin menabung perlu dikembangkan variannya, agar motivasi menabung pada para siswa TK dapat tertanam kuat. Dengan demikian diharapkan setiap siswa akan terus termotivasi untuk melanjutkan kebiasaan menabung hingga dewasa, agar kehidupan keuangannya tertata dengan baik, dan mampu memenuhi setiap tujuan keuangan yang direncanakan.

\section{UCAPAN TERIMA KASIH}

Ucapan terima kasih disampaikan kepada seluruh mahasiswa peserta program Service Learning matakuliah Personal Finance pada semester Gasal 2015/2016 yang telah bekerja keras untuk meng- edukasi para siswa TK dan Bunda TK di sebagian wilayah Siwalankerto dan Pondok Chandra Surabaya dengan memanfaatkan secara optimal media ajar yang dibuat dan yang tersedia. Ucapan terima kasih juga disampaikan kepada para Kepala Sekolah TK. Kyai Ibrahim 1-A, TK. Islam Nur Azizi 3, TK. Az-Zahro, TK. Karya Widya, dan TK. Hidayatullah yang telah memberi kesempatan kepada para mahasiswa Program Manajemen Keuangan Program Studi Manajemen Fakultas Ekonomi Universitas Kristen Petra untuk melakukan edukasi menabung kepada para siswa TK dan edukasi perencanaan keuangan keluarga kepada para Bunda TK.

\section{DAFTAR PUSTAKA}

Ahyani, L. N. (2010). Metode Dongeng dalam Meningkatkan Perkembangan Kecerdasan Moral Anak Usia Prasekolah. Jurnal Psikologi Universitas Muria Kudus, 24-32.

Asuh Anak. (2014). Inilah Cara Mengenalkan Uang kepada Anak. Retrieved Agustus 24, 2016, from Asuh Anak: http://www.asuhanak.com/2015/02/ inilah-cara-mengenalkan-uang-kepada-anak. html

Bidanku. (2016). Manfaat Cerita Dongeng Anakanak Bagi Perkembangan Buah Hati Kita. Retrieved Juli 18, 2016, from Bidanku: http://bidanku.com/manfaat-cerita-dongenganak-anak-bagi-perkembangan-buah-hati-kita

biMBA AIUEO. (2013, Desember 30). Manfaat Mewarnai dan Menggambar bagi Anak. Diakses dari biMBA AIUEO: http://www.bimba-aiueo. $\mathrm{com} /$ manfaat-mewarnai-dan-menggambarbagi-anak/

Fadhilah, N. (2014). Meningkatkan kemampuan motorik halus melalui kegiatan mewarnai di kelompok B TK KKLKMD Sedyo Rukun Bambanglipuro Bantul. Yogyakarta: Fakultas Ilmu Pendidikan Universitas Negeri .

Fitriani, D., \& Reza, M. (2013). Mengembangkan Kegiatan Gerak dan Lagu untuk Meningkatkan Kemampuan Motorik Kasar pada Anak Usia 5-6 Tahun. ejournal.unesa.ac.id, 1-6.

Gunansyah, G. (2010, Nopember 3). Orientasi Penyelenggaraan Pendidikan Dasar Berbasis Pendidikan Karakter. Diakses dari Kompasiana: http://www.kompasiana.com/ www.pgsdunesa.ac.id/orientasi-penyelenggaraanpendidikan-dasar-berbasis-pendidikankarakter_55003ec5a33311177351019f

Kementerian Pendidikan Nasional. (2012). Pedoman Pendidikan Karakter pada Pendidikan Anak Usia Dini. Jakarta: Direktorat Jenderal Pendidikan Anak Usia Dini, Onformal, Dan Informal. 
Mulyadi, S., \& Trizki, L. (2012). Financial Parenting: Menjadikan Anak Cerdas dan Cermat Mengelola Uang. Jakarta: Noura Books.

Nakita. (2016). 6 Manfaat Bermain Peran Bagi Kecerdasan Anak. Retrieved Agustus 22, 2016, from Nakita: http://www.tabloid-nakita.com/ $\mathrm{read} / 4154 / 6$-manfaat-bermain-peran-bagikecerdasan-anak-

Rachmayanti, R. D. (2011). Penggunaan Media Panggung Boneka dalam Pendidikan Personal Hygiene Cuci Tangan Menggunakan Sabun di Air Mengalir. Promosi Kesehatan, 1-13.

Risnawati, V. (2012). Optimalisasi Pendidikan Karakter Anak Usia Dini Melalui Sentra Main Peran di Taman Kanak-kanak Padang. Pesona PAUD, 1-10.
Sitepu, A. L. (2013, Juli 25). 5 Langkah Mendidik Anak agar Mau Menabung Sejak Dini. Retrieved Juli 18, 2016, from Wolipop: http:// wolipop.detik.com/read/2013/07/25/104711/ 2313837/857/5-langkah-mendidik-anak-agarmau-menabung-sejak-dini-

Unilever. (2016). Rinso. Diakses dari Kegiatan Mewarnai bagi Pertumbuhan Anak Balita: https://www.rinso.co.id/perkembangananak/kegiatan-mewarnai-bagi-pertumbuhananak-balita/

Verawati. (2015, Januari 22). Cerdaskan Anak Dengan Dongeng. Retrieved Juli 18, 2016, from Pustaka Pelangi: http://www.pustakapelangi. com/cerdaskan-anak-dengan-dongeng/

Wijayanti, W. (2008). Peran pengelolaan pendidikan di Taman Kanak-kanak. Fondasia, 1-12. 